\title{
Impact of an improved WRF urban canopy model on diurnal air temperature simulation over northern Taiwan
}

\author{
Chuan-Yao Lin ${ }^{1}$, Chiung-Jui Su ${ }^{1}$, Hiroyuki Kusaka ${ }^{2}$, Yuko Akimoto ${ }^{2}$, Yang-Fan Sheng ${ }^{1}$, Jr-Chuan Huang ${ }^{3}$, and \\ Huang-Hsiung Hsu ${ }^{1}$ \\ ${ }^{1}$ Research Center for Environmental Changes, Academia Sinica, Taipei, Taiwan \\ ${ }^{2}$ Graduate school of Life and Environmental Sciences, and Center for Computational Sciences, University of Tsukuba, \\ Tsukuba, Japan \\ ${ }^{3}$ Department of Geography, National Taiwan University, Taipei, Taiwan \\ Correspondence to: Chuan-Yao Lin (yao435@rcec.sinica.edu.tw)
}

Received: 10 June 2015 - Published in Atmos. Chem. Phys. Discuss.: 21 October 2015

Revised: 4 January 2016 - Accepted: 29 January 2016 - Published: 16 February 2016

\begin{abstract}
This study evaluates the impact of urbanization over northern Taiwan using the Weather Research and Forecasting (WRF) Model coupled with the Noah land-surface model and a modified urban canopy model (WRF-UCM2D). In the original UCM coupled to WRF (WRF-UCM), when the land use in the model grid is identified as "urban", the urban fraction value is fixed. Similarly, the UCM assumes the distribution of anthropogenic heat $(\mathrm{AH})$ to be constant. This may not only lead to over- or underestimation of urban fraction and $\mathrm{AH}$ in urban and non-urban areas, but spatial variation also affects the model-estimated temperature. To overcome the abovementioned limitations and to improve the performance of the original UCM model, WRF-UCM is modified to consider the 2-D urban fraction and AH (WRFUCM2D).

The two models were found to have comparable temperature simulation performance for urban areas, but large differences in simulated results were observed for non-urban areas, especially at nighttime. WRF-UCM2D yielded a higher correlation coefficient $\left(R^{2}\right)$ than WRF-UCM $(0.72$ vs. 0.48 , respectively), while bias and RMSE achieved by WRFUCM2D were both significantly smaller than those attained by WRF-UCM (0.27 and 1.27 vs. 1.12 and 1.89 , respectively). In other words, the improved model not only enhanced correlation but also reduced bias and RMSE for the nighttime data of non-urban areas. WRF-UCM2D performed much better than WRF-UCM at non-urban stations with a low urban fraction during nighttime. The improved simulation performance of WRF-UCM2D in non-urban ar-
\end{abstract}

eas is attributed to the energy exchange which enables efficient turbulence mixing at a low urban fraction. The result of this study has a crucial implication for assessing the impacts of urbanization on air quality and regional climate.

\section{Introduction}

The significant interactions between urbanization and the atmospheric environment have become increasingly evident. The important impact of changes in land use and land cover (LULC) on precipitation and climate has also been much emphasized (e.g., Kalnay and Cai, 2003; Koster et al., 2004; Feddema et al., 2005; Lin et al., 2008a, 2011; IPCC, 2007, 2013; Wang et al., 2014). It is estimated that the world's population will rise to 9.3 billion in 2050 (http://esa.un.org/ unpd/wup/index.htm). Furthermore, the most recent report on world urbanization prospects published by the United Nations indicated that in 2014, $54 \%$ of the world's population resided in urban areas (http://esa.un.org/unpd/wup/ Highlights/WUP2014-Highlights.pdf); by 2050, the world's urban population is projected to be $66 \%$. Rapid urbanization has resulted in environmental problems including increasing energy consumption and air pollution, deterioration of visibility, a significant urban heat island (UHI) effect, urban heavy rainfall, and even local (regional) climate change (Oke, 1982; Grimmond and Oke, 1995; Atkinson, 2003; Arnfield, 2003; Jin et al., 2005; Feddema et al., 2005; Ren et al., 2007; Corburn, 2009; Kusaka et al., 2012b, 2014; Kang et 
al., 2014; Huszar et al., 2014). In particular, the UHI effect is a critical factor influencing the intensity and duration of heat wave events (Tan et al., 2010; Rizwan et al., 2008; Kunkel et al., 1996). It is expected that under the trend of global warming, the impact of urbanization will become increasingly significant and far-reaching.

The UHI is a city that is significantly warmer than its surrounding rural areas; this is caused by LULC changes and human activities. The LULC changes bring about variations in the physical properties of land, such as albedo, surface roughness, thermal inertia, and evapotranspiration efficiency, and in turn alter the climate system. In modeling studies, detailed information on land use and urban parameters are critical for simulation of the UHI effect. Chen et al. (2011) reviewed the integration of the Weather Research and Forecasting (WRF) model with different urban canopy schemes including bulk urban parameterization (Liu et al., 2006), the single-layer urban canopy model (UCM) (Kusaka and Kimura, 2004), and multilayer urban canopy and indooroutdoor exchange models (Martilli et al., 2002). In recent years, the WRF Model coupled with the Noah land-surface model and the UCM (WRF-UCM) (Tewari et al., 2006; Holt and Pullen, 2007; Lin et al., 2008b) has been successfully applied to research on the UHI effect in megacites of Japan (Kusaka et al., 2012a), the United States (Liu et al., 2006; Lo et al., 2007), China (Miao et al., 2009), and Taiwan (Lin et al., 2008b, 2011). Studies conducted in Taiwan have found that WRF-UCM can improve the simulation of UHI intensity, boundary layer development, land-sea breeze (Lin et al., 2008b), and precipitation (Lin et al., 2011). However, the existing UCM (Kusaka and Kimura, 2004) when coupled with the WRF Model still has some limitations.

In the original UCM, when the land use in the model grid is identified as "urban", the urban fraction value is fixed. Yet in reality, the categorization of land use and land cover is far more complex and the existing model is still too rough to reflect the exact land use in urban and non-urban areas. Similarly, the UCM assumes the distribution of anthropogenic heat (AH) to be constant and includes only the urban data. Such simplification may lead to over- or underestimation, thus affecting the accuracy of model temperature estimations (detailed description in Sect. 2.2). To overcome the abovementioned limitations and to improve the performance of the original UCM model, WRF-UCM is modified to consider the 2-D urban fraction and AH. The modified version of UCM (hereafter referred to as WRF-UCM2D) is then employed to assess the impact of urbanization on Taipei City, and its simulation performance is compared against that of WRF-UCM.

The Taipei metropolis, located in northern Taiwan (Fig. 1), experiences a significant UHI effect due to its geographical position in a basin surrounded by high mountains. Made up of both Taipei City and New Taipei City, the metropolis has a very high population density; more than six million people, about one quarter of the total population of Taiwan, inhabit this small basin of $243 \mathrm{~km}^{2}$ situated at $20 \mathrm{~m}$ elevation above sea level. The high population density and complex geographic structure of the Taipei metropolis intensifies the UHI effect, which is significantly more severe than that in other cities and metropolises of similar area around the world. Chen et al. (2007) reported an increase in daily mean temperature of $1.5^{\circ} \mathrm{C}$ in Taipei City due to urbanization. Lin et al. (2008b) found that the UHI intensity in northern Taiwan could be as high as $4-6^{\circ} \mathrm{C}$.

The rest of the paper is organized as follows. Section 2 describes in detail the original WRF-UCM, with its limitations discussed and suggestions for improvements made. Section 3 evaluates the performance of WRF-UCM2D when applied to a simulation study on the impact of urbanization over northern Taiwan. Section 4 further examines the factors influencing model performance in non-urban areas during nighttime. Section 5 contains the summary and conclusion of this study.

\section{WRF urban canopy model}

The WRF Model (Version 3.2.1), described in detail by Skamarock et al. (2008), is a widely used mesoscale meteorological model. For a better understanding of the UHI effect and for a more accurate estimation of energy consumption in urban areas, an advanced Noah (Ek et al., 2003) landsurface-hydrology model (LSM) has been coupled to the WRF Model (Chen et al., 2004; Tewari et al., 2006). The Noah-LSM provides surface sensible and latent heat fluxes as well as ground surface temperature in the lower boundary (Chen and Dudhia, 2001; Ek et al., 2003). To incorporate the physical processes involved in the exchange of heat, momentum, and water vapor in the mesoscale model, the urban canopy model (UCM) has been coupled with the Noah-LSM in the WRF Model (Kusaka et al., 2006; Tewari et al., 2006).

The original UCM coupled with the WRF Model is a single-layer model for evaluating the effects of urban geometry on surface energy balance and wind shear in urban regions (Kusaka et al., 2001; Kusaka and Kimura 2004; Chen et al., 2011). This model takes into account shadows from buildings, canyon orientation, diurnal variation of azimuth angle, reflection of short- and long-wave radiation, the wind profile in the canopy layer, anthropogenic heating associated with energy consumption by human activities, and multilayer heat transfer equation for roof, wall, and road surfaces. Kusaka and Kimura (2004) provide a detailed description of the original UCM.

\subsection{WRF Model configuration}

In this study, the Mellor-Yamada-Janijć (MYJ) planet boundary layer scheme was adopted. The cloud microphysics used in this simulation by the WRF Model was the single-moment 6-class (WSM6) microphysics scheme (Hong and Lim, 2006). The rapid radiative transfer model 


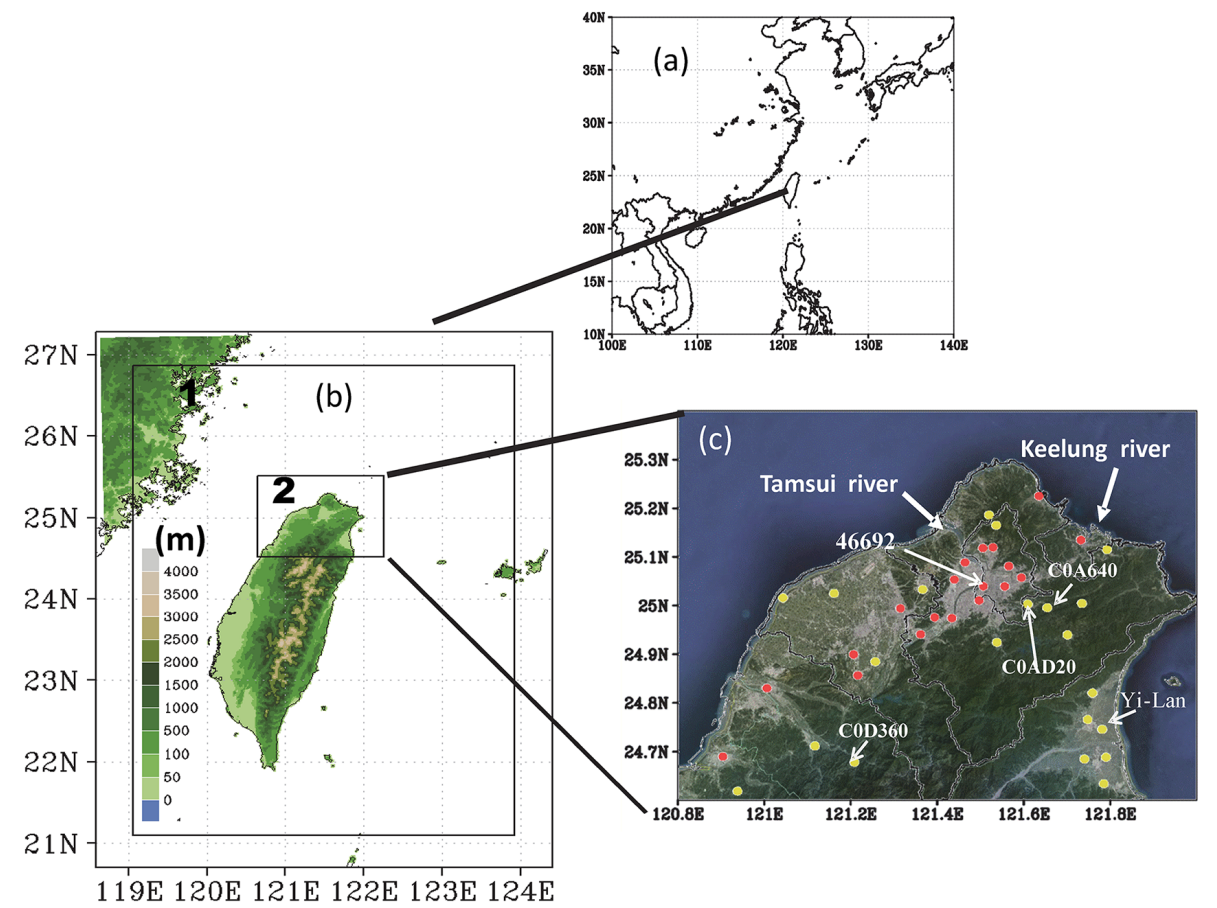

Figure 1. Location of Taiwan (a), simulation domains (b), and locations of urban (red dots) and non-urban (yellow dots) meteorological stations (c) in northern Taiwan.

(RRTMG) was used for both long-wave and shortwave radiation schemes.

The initial and boundary conditions for the WRF were obtained using data sets of the Global Forecast System from the National Center for Environmental Prediction (NCEP-GFS) $0.5^{\circ} \times 0.5^{\circ}$ analysis data sets at 6-hour intervals. Two nest domains were constructed with spatial grid resolutions of 3 and $1 \mathrm{~km}$, which contained $150 \times 199$ and $151 \times 100$ grid boxes, respectively, from north to south and east to west. Both domains have 45 vertical levels, and the model top is set at $10 \mathrm{hPa}$. To ensure that the meteorological fields are well simulated, the 4-D data assimilation (FDDA) scheme was activated in a coarse domain using the NCEP-GFS analysis data. In the following discussion, only the finer domain of $1 \mathrm{~km}$ resolution is shown in the comparison with the observed data.

\subsection{Limitations of UCM and suggestions for improvement}

\subsubsection{Urban fraction}

In the original UCM, if the model grid is categorized as "urban", it indicates that urban land use accounts for the largest percentage of land use within this model grid. However, such classification of land use may lead to oversimplification, resulting in land uses other than urban within this model grid being ignored. Moreover, the urban fraction within a model grid categorized as "urban" is fixed. For instance, in this study, the urban fraction is fixed at 0.7. Problems of overand underestimation will arise because of the difference in percentage of urban land use in city centers and suburban areas. City centers are likely to have a higher urban fraction above 0.7 , while suburban areas may have a lower urban fraction below 0.7 . With both categorized as "urban" and given the same urban fraction, it may result in urban land use in city center not being fully accounted for, while that in suburban areas is overestimated. Furthermore, there also exist differences in urban parameters, such as building height, sky view factor, heat capacity, and thermal conductivity, between city centers and suburban areas both categorized as "urban" in the model grid. In reality, land use over a large area is far more complex; and the current UCM cannot adequately reflect the actual situation, even with some areas left out of the picture. These limitations in the original UCM when applied to UHI simulation or urban boundary delineation will inevitably affect the accuracy of results obtained.

To overcome the abovementioned problems, this study generated the 2-D spatial distribution map of urban fraction at $1 \mathrm{~km}$ resolution according to land use data at $100 \mathrm{~m}$ resolution (Fig. 2a) obtained from the National Land Surveying and Mapping Center, Taiwan, (http://www.nlsc.gov.tw/ websites/nlsceng/i_ext/default.aspx) for 2006. Figure $2 b$ and $c$ show the spatial distribution of urban areas obtained using WRF-UCM and WRF-UCM2D, respectively. As can be seen, WRF-UCM2D provided a more detailed and accurate spatial distribution of areas with an urban fraction ranging 

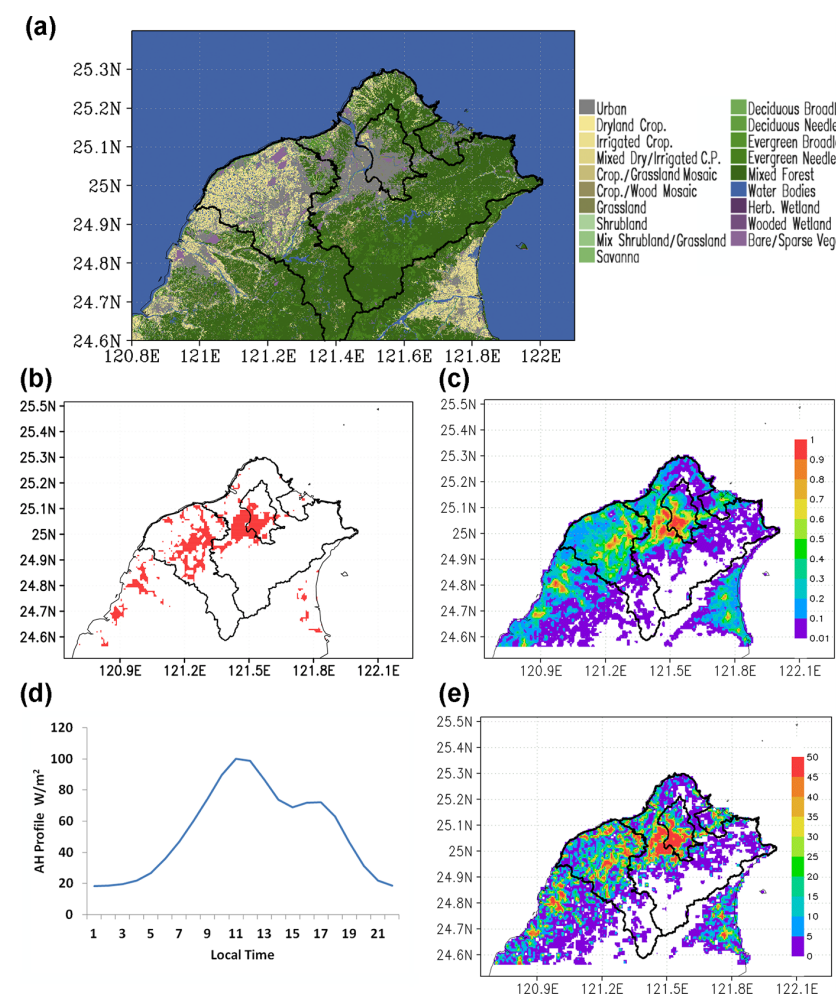

Figure 2. Panel (a): land use data at $100 \mathrm{~m}$ resolution obtained from the National Land Surveying and Mapping Center, Taiwan, for 2006. Spatial distribution of urban areas simulated at $1 \mathrm{~km}$ resolution (b) by WRF-UCM with an urban fraction fixed at 0.7 and (c) by WRFUCM2D with an urban fractions ranging from 0.01 to 1.0. Panel (d): diurnal variation of AH used in model simulation. Panel (e): spatial distribution of $\mathrm{AH}$ ranging from 0 to $50 \mathrm{~W} \mathrm{~m}^{-2}$ simulated by WRF-UCM2D at $1 \mathrm{~km}$ resolution. The following abbreviations are used in the legend: Crop. - cropland; C. P. - cropland and pasture; Herb. - herbaceous.

from 0.01 to 1.0. With the improved model, the oversimplified results can be avoided, with the percentage of urbanization in the model grids more accurately identified according to the actual land use, not only in the city center but also in rural small towns.

\subsubsection{Anthropogenic heat}

Similar problems of over- and underestimation occur when deriving the spatial distribution of anthropogenic heat (AH) with the original UCM. Like the urban fraction, AH is defined as constant and only data of defined urban areas are included. For instance, in this study, the diurnal mean $\mathrm{AH}$ is fixed at $50 \mathrm{~W} \mathrm{~m}^{-2}$. Hence, for a model grid categorized as "urban" in the original UCM model, the AH in all urban areas within the model grid (areas marked as red in Fig. 2b) will be the same. In fact, AH sources include industry, buildings, vehicles (transportation), and even the metabolism of plants, animals, and humans (Sailor and Lu, 2004; Grimmond, 1992; Sailor, 2011; Liao et al., 2014). Needless to say, the spatial distribution of $\mathrm{AH}$ in a city center is different from that in a rural small town. Again, the oversimplification cannot reflect the actual situation, which will in turn undermine the simulation performance.
The same improvement approach for the urban fraction is adopted. That is, a 2-D spatial distribution map of AH at $1 \mathrm{~km}$ resolution is generated according to building density data obtained from the National Land Surveying and Mapping Center, Taiwan, for 2006. Figure $2 \mathrm{~d}$ and e show the data on AH distribution provided by WRF-UCM and WRFUCM2D, respectively. As can be seen, with the AH value assumed constant (a daily mean of $50 \mathrm{~W} \mathrm{~m}^{-2}$ in this study), WRF-UCM can only offer a diurnal profile, showing that $\mathrm{AH}$ peaked around noon at a temperature almost double the mean $\mathrm{AH}$ value. By contrast, by using WRF-UCM2D, the spatial distribution of $\mathrm{AH}$ over the entire area studied can be obtained. Shown in Fig. 2e are areas with $\mathrm{AH}$ ranging from 0 to $50 \mathrm{~W} \mathrm{~m}^{-2}$, giving more detailed information at a finer resolution.

To assess the effectiveness of the improved approaches, WRF-UCM2D is applied to the simulation study on the impact of urbanization in northern Taiwan. Comparison in simulation performance between the original and improved $\mathrm{WRF}-\mathrm{UCM}$ is also made. 


\section{Model evaluation and simulation results}

To assess the impact of urbanization over northern Taiwan and to evaluate the model performance, this study examined a heat wave event that occurred on 10 July 2012 in Taipei City. In terms of land-use categorization, Taipei City was classified as "high-intensity residence" by the UCM. Stable and non-precipitation weather conditions were selected to do this study. The two models were run from 00:00 UTC (08:00 LST) 7 July 2012 for a total of $96 \mathrm{~h}$ until 00:00 UTC (08:00 LST) 11 July 2012. A $24 \mathrm{~h}$ spin-up is required in the simulation, meaning that only data starting from 8 to 11 July 2012 were analyzed.

Figure 3a shows the surface weather map at 00:00 UTC (08:00 LST) on 10 July 2012 derived through re-analysis of NCEP data. As can be seen, a high-pressure system dominated the weather conditions and southwesterly winds prevailed on that day. The Central Weather Bureau (CWB) reported a maximum air temperature of $38.3{ }^{\circ} \mathrm{C}$ at station 46692 (see Fig. 1c for location) in Taipei City. The wind direction along Tamsui River and Keelung River (see Fig. 1c for location) was mainly northwest (sea breeze) during daytime and southeast (land breeze) during nighttime (not shown). This is a typical heat wave event during summer, with a high surface air temperature exceeding $35^{\circ} \mathrm{C}$ during daytime.

\subsection{Air temperature}

Figure $3 \mathrm{~b}$ displays the variations in mean hourly air temperature observed by the CWB and simulated at $2 \mathrm{~m}$ elevation using WRF-UCM2D. The observed data were from 19 urban stations (red dots in Fig. 1c) and 21 non-urban stations (yellow dots in Fig. 1c). Stations located in the innermost model grid with an urban fraction $\geq 5$ are categorized as "urban", while those with an urban fraction $\leq 4$ are categorized as "non-urban". As can be seen, not only do the observed and simulated data show the same trend, the two values are also very close for both urban and non-urban stations. In other words, simulation by WRF-UCM2D can accurately capture diurnal variations in air temperature of the entire area in the studied period. Figure 3c, d, and e show the observation air temperature at 11:00, 12:00, and 13:00 LST, respectively. At 12:00 LST, of the 19 urban stations, 12 recorded temperatures of $36^{\circ} \mathrm{C}$ and above, with 6 stations in Taipei City and 6 stations in New Taipei City. In contrast, none of the non-urban stations recorded temperature exceeding $35^{\circ} \mathrm{C}$. In other words, the Taipei basin was severely affected by the heat wave (i.e., air temperature $>35^{\circ} \mathrm{C}$ ). At 13:00 LST, one urban station (marked gray in Fig. 3e) even recorded the highest of $38^{\circ} \mathrm{C}$.

\subsection{Spatial distribution of air temperature}

Figure 4 compares the spatial distribution of air temperature simulated by WRF-UCM (Fig. 4a, d, and g), that simulated by WRF-UCM2D (Fig. 4b, e, and h), and the difference between WRF-UCM2D and WRF-UCM (Fig. 4c, f, and i) at 11:00, 12:00, and 13:00 LST, respectively on 10 July 2012. Though the values are similar, the results obtained by WRF-UCM2D include temperatures higher than $36^{\circ} \mathrm{C}$, which are not found in the simulation of WRF-UCM. As seen in Fig. 3c, some areas in the heart of Taipei City have a temperature exceeding $36^{\circ} \mathrm{C}$ at $11: 00 \mathrm{LST}$, while the simulated temperatures for these areas as shown in Fig. 4a peak at $36^{\circ} \mathrm{C}$. A similar phenomenon is observed for simulations at 12:00 and 13:00 LST. As seen in Fig. 4e, there are areas within Taipei City with a temperature exceeding $37^{\circ} \mathrm{C}$ at 12:00 LST, but the highest temperature shown in Fig. $4 \mathrm{~d}$ is only $37^{\circ} \mathrm{C}$. Although areas with temperature exceeding $37^{\circ} \mathrm{C}$ are simulated by both models, WRF-UCM2D yields more areas with such a high temperature (Fig. 4h) than WRF-UCM (Fig. 4g). Moreover, the spatial distributions of air temperature shown in Fig. 4b, e, and $\mathrm{h}$ bear closer resemblance to Fig. 3c, d, and e, respectively, than to those shown in Fig. 4a, d, and g, implying that the simulated results of WRF-UCM2D match the observed temperature more closely than those of WRF-UCM. Taken together, these findings reveal an underestimation in the simulated temperature obtained by WRF-UCM, evidencing a better simulation performance of WRF-UCM2D. It is worth noting that despite its superior simulation performance, WRFUCM2D fails to capture the highest temperature of $38^{\circ} \mathrm{Cob}$ served at one station at 13:00 LST (Fig. 3e).

\subsection{Bias, root mean square error (RMSE), and correlation coefficient $\left(\boldsymbol{R}^{2}\right)$}

Figure 5 shows the scatterplots of observed and simulated temperatures at the 19 urban stations. Bias, root mean square error (RMSE), and correlation coefficient $\left(R^{2}\right)$ of the observed and simulated data were also calculated using the following equations.

$$
\begin{aligned}
\text { BIAS } & =\frac{\sum_{i=1}^{n} X-\bar{X}}{n}, \\
\text { RMSE } & =\sqrt{\frac{\sum_{i=1}^{n}(X-\bar{X})^{2}}{n},}
\end{aligned}
$$

where $X$ denotes the simulated results and $\bar{X}$ stands for the observed data. The calculated results are shown both in Fig. 5 and Table 1 . As can be seen, the simulated results obtained by WRF-UCM (Fig. 5a) and WRF-UCM2D (Fig. 5b) are close, with an insignificant difference in their bias, RMSE, and $R^{2}$ $\left(-0.03^{\circ} \mathrm{C}, 1.05^{\circ} \mathrm{C}\right.$, and 0.87 vs. $0.17^{\circ} \mathrm{C}, 0.99^{\circ} \mathrm{C}$, and 0.89 , 


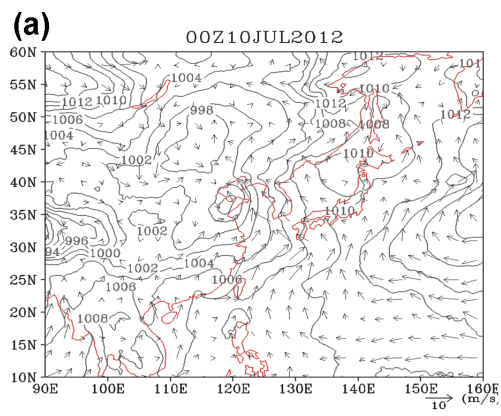

(c)

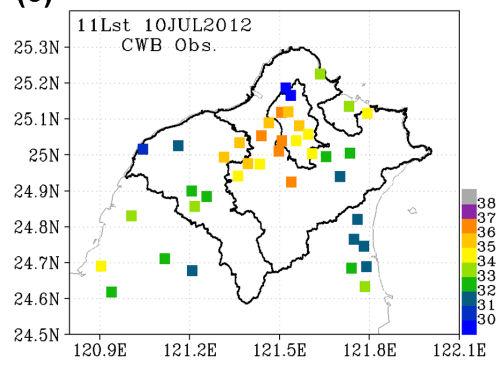

(d)
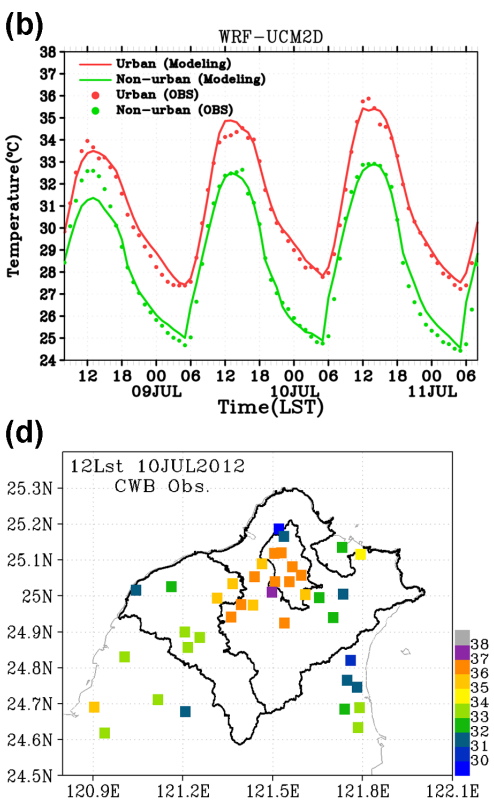

(e)

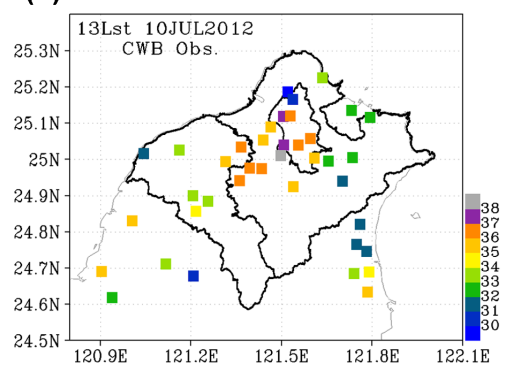

Figure 3. Panel (a): surface weather map at 08:00 LST, 10 July 2012. Panel (b): mean hourly air temperature simulated by WRF-UCM2D and observed at 19 urban stations and 21 non-urban stations (red dots and yellow dots, respectively, in Fig. 1c) during the study period. Spatial distribution of air temperature observed at (c) 11:00 LST, (d) 12:00 LST, and (e) 13:00 LST on 10 July 2012 at various meteorological stations. Unit is degrees Celsius.

respectively) as listed in Table 1. In other words, the two models have a comparable simulation performance for urban areas. However, a difference in model performance is found in a more detailed comparison between daytime (Fig. $5 \mathrm{c}-\mathrm{d}$ ) and nighttime (Fig. 5e-f) results. According to Table 1, the RMSE between simulation and observation is less than $1{ }^{\circ} \mathrm{C}$ during daytime but more than $1^{\circ} \mathrm{C}$ during nighttime. The $R^{2}$ for WRF-UCM2D and WRF-UCM is 0.9 and 0.89 , respectively, during daytime but decreases to 0.65 and 0.55 , respectively, during nighttime.

The same comparison was made for simulated and observed temperatures at the 21 non-urban stations. Figure 6 show the scatterplots, and Table 2 lists the bias, RMSE, and $R^{2}$ values. The trends and results obtained are similar to those for the urban stations. First, WRF-UCM2D outperforms WRF-UCM in terms of BIAS, RMSE, and $R^{2}$ values $\left(0.11^{\circ} \mathrm{C}, 1.3{ }^{\circ} \mathrm{C}\right.$, and 0.86 vs. $0.33^{\circ} \mathrm{C}, 1.62^{\circ} \mathrm{C}$, and 0.82 , respectively) as shown in Table 2. Second, larger differences in model performance are observed for nighttime data. WRF-
UCM2D yielded a higher $R^{2}$ than WRF-UCM ( 0.72 vs. 0.48 , respectively), while the bias and RMSE produced by WRF-UCM2D were both significantly smaller than those attained by WRF-UCM (0.27 and 1.27 vs. 1.12 and 1.89 , respectively). In other words, the improved model not only enhanced correlation but also reduced bias and RMSE for the nighttime data of non-urban areas.

Taken together, the above results reveal comparable model performance for daytime urban data, while large differences in simulated results are observed for nighttime non-urban data.

\subsection{Diurnal temperature variation}

Figure 7 shows the performance of the two models in simulating mean diurnal variation of temperature at the 21 nonurban stations (yellow dots in Fig. 1c). The urban fraction of these non-urban stations in the model grids are all less than 0.4 . As shown in the figure, the two models yielded very sim- 
(a)

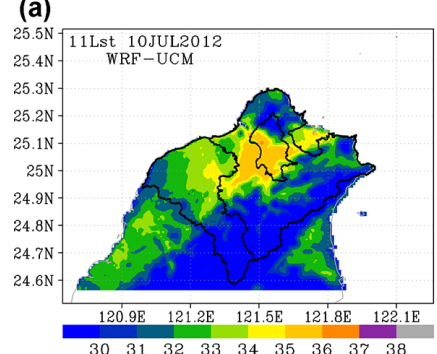

(d)

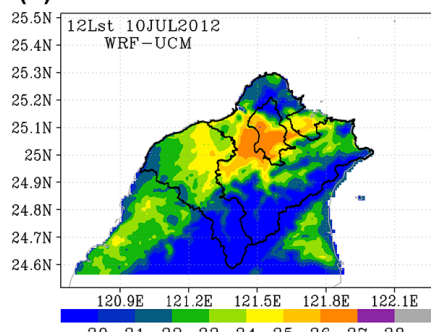

(g)

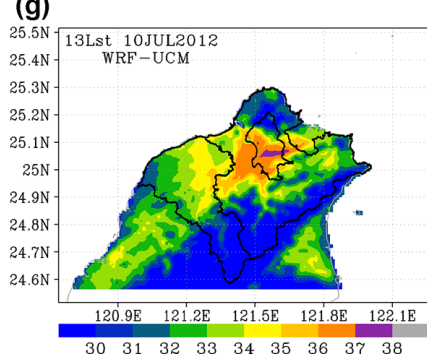

(b)

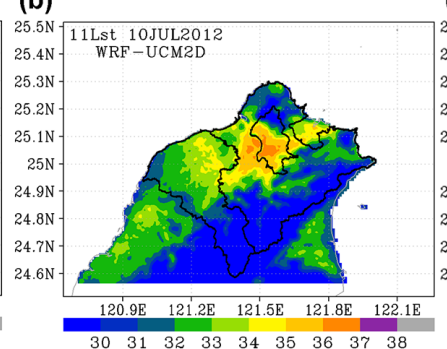

(e)

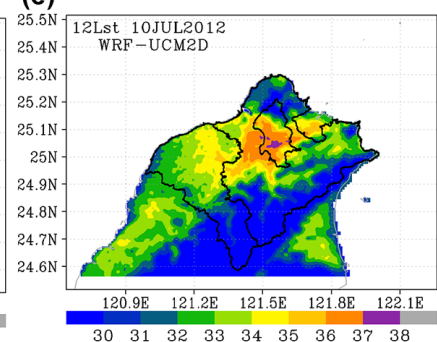

(h)

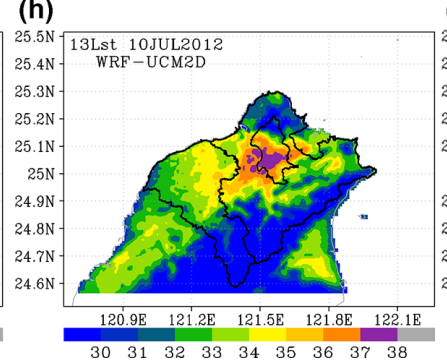

(c)

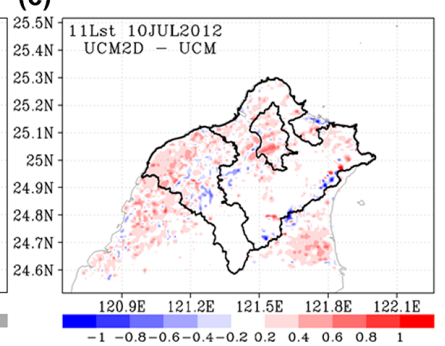

(f)

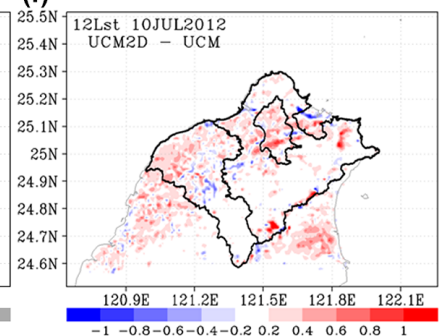

(i)

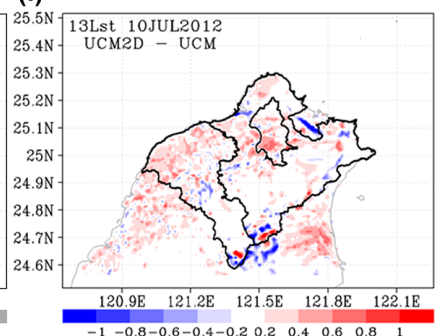

Figure 4. Spatial distribution of air temperature on 10 July 2012 simulated by WRF-UCM and WRF-UCM2D and the difference between WRF-UCM2D and WRF-UCMat for (a, b, c) 11:00 LST, (d, e, f) 12:00 LST, and (g, h, i) 13:00 LST. Unit is degrees Celsius.

Table 1. Bias, RMSE, and $R^{2}$ calculated using simulated temperatures at 19 urban stations for 8-11 July 2012, for daytime, and for nighttime obtained by WRF-UCM and WRF-UCM2D.

\begin{tabular}{|c|c|c|c|c|c|c|}
\hline \multirow[t]{2}{*}{ Urban } & \multicolumn{2}{|c|}{ 8-11 July 2012} & \multicolumn{2}{|c|}{ Daytime } & \multicolumn{2}{|c|}{ Nighttime } \\
\hline & WRF-UCM & WRF-UCM2D & WRF-UCM & WRF-UCM2D & WRF-UCM & WRF-UCM2D \\
\hline $\operatorname{BIAS}\left({ }^{\circ} \mathrm{C}\right)$ & -0.03 & 0.17 & -0.1 & 0.12 & 0.09 & 0.26 \\
\hline $\operatorname{RMSE}\left({ }^{\circ} \mathrm{C}\right)$ & 1.05 & 0.99 & 0.94 & 0.92 & 1.2 & 1.08 \\
\hline$R^{2}$ & 0.87 & 0.89 & 0.89 & 0.9 & 0.55 & 0.65 \\
\hline
\end{tabular}

ilar results of almost the same trend with major discrepancy observed between 20:00 and 05:00 LST. During nighttime, the mean temperature differences simulated by WRF-UCM range from 1 to $1.5^{\circ} \mathrm{C}$, while those by WRF-UCM2D are mostly below $0.5^{\circ} \mathrm{C}$. Again, the results indicate comparable model performance for daytime data but large differences in simulated results for nighttime data. In other words, the performance of WRF-UCM2D is much better than WRF-UCM at non-urban stations with a low urban fraction during nighttime

Furthermore, after 05:00 LST, the temperature simulated by WRF-UCM2D rises abruptly, approaching that simulated by WRF-UCM. This sudden rise can be attributed to the ur- ban elements present at these stations, which absorb shortwave radiation after sunrise, causing increase in temperature.

Figure $8 \mathrm{a}, \mathrm{b}$, and $\mathrm{c}$ further compare the model performance in simulating the diurnal temperature variation at three nonurban stations, namely C0AD20, C0A640, and C0D360 (see Fig. 1c for location), with urban fractions of $0.313,0.127$, and 0.04 , respectively. As seen in Fig. 8a, the simulated temperatures are fairly close to the observed ones at station COAD20, except for overestimation of $1-2{ }^{\circ} \mathrm{C}$ by WRFUCM during nighttime. At station C0A640, the same phenomenon is observed but with a larger overestimation. As shown in Fig. 8b, both simulation and observed temperatures are similar and show the same trend, but the nighttime tem- 
Table 2. Bias, RMSE, and $R^{2}$ calculated using simulated temperatures at 21 non-urban stations for $8-11$ July 2012 , for daytime, and for nighttime obtained by WRF-UCM and WRF-UCM2D.

\begin{tabular}{lrrrrrrrr}
\hline \multirow{2}{*}{ Non-urban } & \multicolumn{2}{c}{$8-11$ July 2012 } & & \multicolumn{2}{c}{ Daytime } & & \multicolumn{2}{c}{ Nighttime } \\
\cline { 2 - 3 } & WRF-UCM & WRF-UCM2D & & WRF-UCM & WRF-UCM2D & & WRF-UCM & WRF-UCM2D \\
\hline BIAS $\left({ }^{\circ} \mathrm{C}\right)$ & 0.33 & 0.11 & & -0.13 & 0.01 & & 1.12 & 0.27 \\
RMSE $\left({ }^{\circ} \mathrm{C}\right)$ & 1.62 & 1.3 & & 1.45 & 1.32 & & 1.89 & 1.27 \\
$R^{2}$ & 0.82 & 0.86 & & 0.82 & 0.84 & & 0.48 & 0.72 \\
\hline
\end{tabular}

(a)

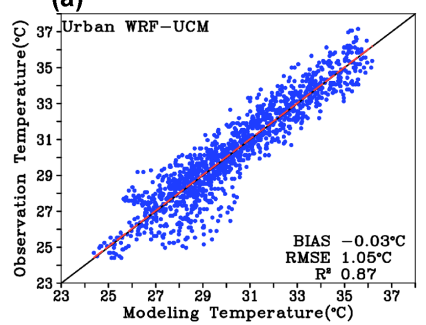

(c)

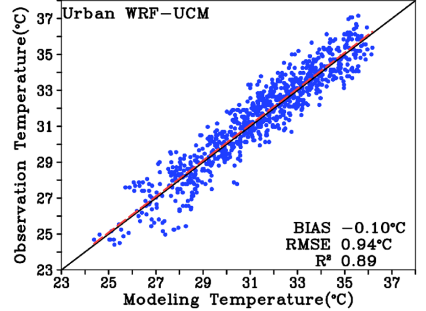

(e)

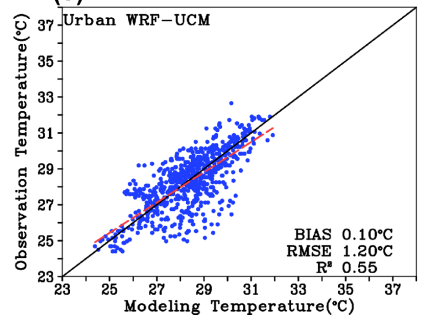

(b)

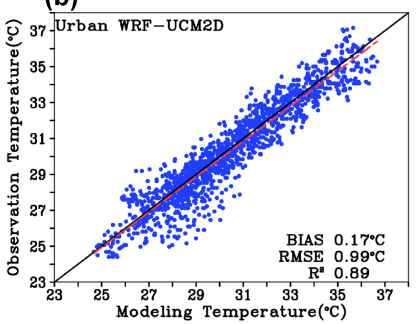

(d)

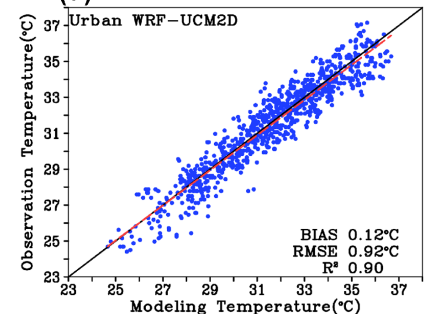

(f)

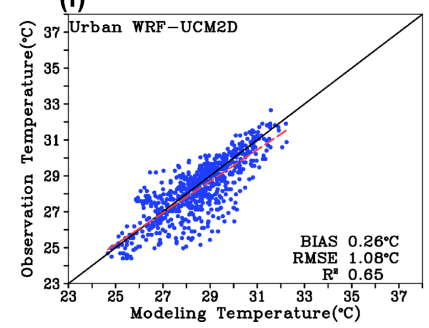

Figure 5. Scatterplots between observed and simulated temperatures at 19 urban stations with bias, RMSE, and $R^{2}$ calculated using simulated temperatures of $(\mathbf{a}, \mathbf{b})$ the entire study period, $(\mathbf{c}, \mathbf{d})$ daytime, and (e, f) nighttime obtained by WRF-UCM and WRFUCM2D, respectively.

perature simulated by WRF-UCM is about $2{ }^{\circ} \mathrm{C}$ higher than the observed temperature. Greater deviations from observed temperature are found at station C0D360 with an urban fraction of only 0.04. As seen in (Fig. 8c), while WRF-UCMsimulated air temperatures during nighttime show small fluctuations, they are seriously overestimated by $4-5^{\circ} \mathrm{C}$ at midnight and in the early morning. In contrast, WRF-UCM2Dsimulated air temperatures match more closely those observed at these three non-urban stations and show the same trend of fluctuations, despite the underestimation at station C0D360 during nighttime. Again, the abovementioned
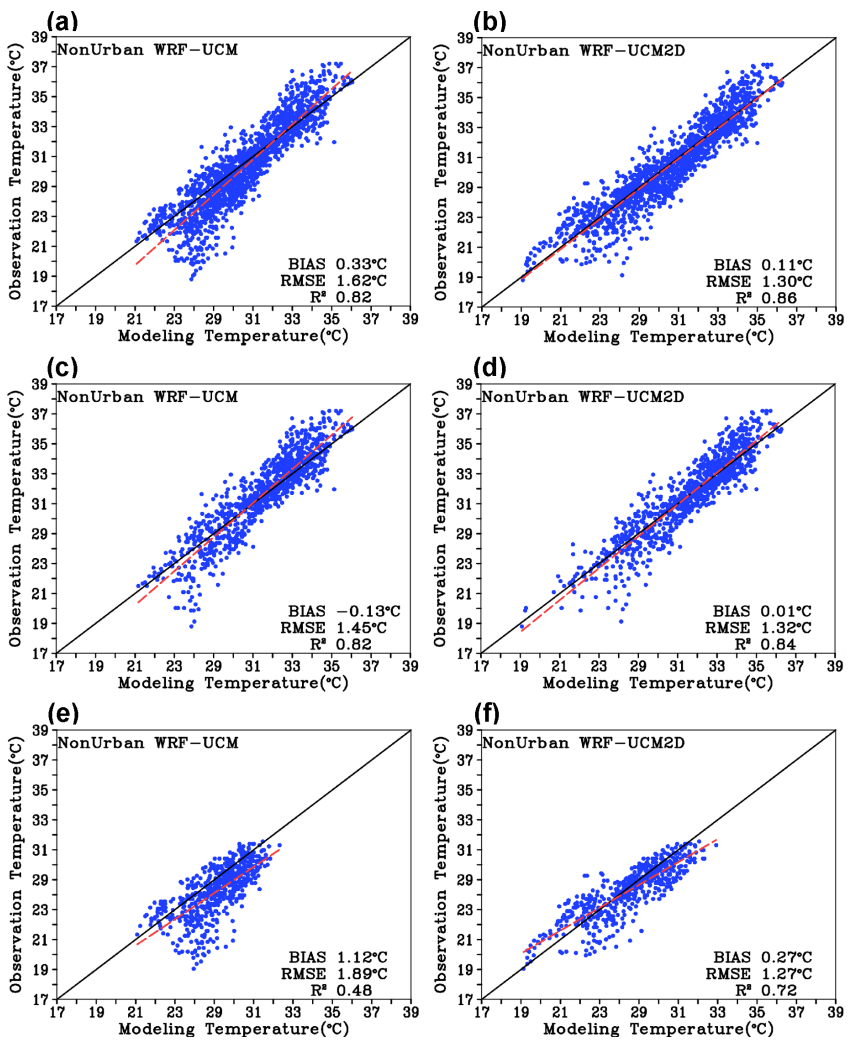

Figure 6. Scatterplots between observed and simulated temperatures at 21 non-urban stations with bias, RMSE, and $R^{2}$ calculated using simulated temperatures of $(\mathbf{a}, \mathbf{b})$ the entire study period, $(\mathbf{c}, \mathbf{d})$ daytime, and (e, f) nighttime obtained by WRF-UCM and WRFUCM2D, respectively.

findings evidence better simulation performance of WRFUCM2D, especially during nighttime.

Moreover, further examination of Fig. 8 reveals a larger difference in nighttime temperature between simulation and observation in model grids of smaller urban fractions, indicating increasing deviation with a decreasing urban fraction at night. Hence, the analysis below focuses on the relationship between urban fraction and model performance between 19:00 and 05:00 LST. 


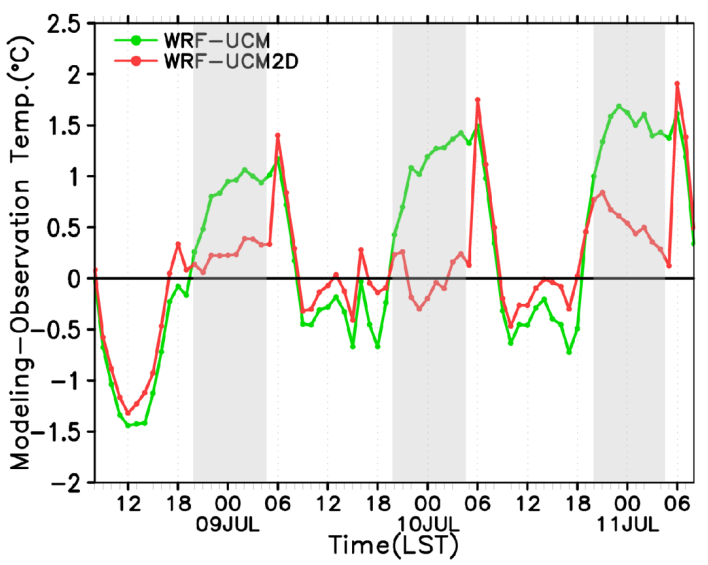

Figure 7. Difference between simulated and observed mean diurnal variation of temperature at 21 non-urban stations.

\subsection{Performance for 1-month simulation in July 2012}

To assess the model performance of a longer time period, a 1-month simulation was also conducted. Bias, RMSE, and $R^{2}$ were calculated using simulated temperatures at 21 nonurban stations (Table 3) and 19 urban stations (Table 4) for the month of July 2012 , for daytime, and for nighttime obtained by WRF-UCM and WRF-UCM2D. The numbers in parentheses were analysis results after the exclusion of model data where simulated rainfall was found to be present. Similarly, WRF-UCM2D showed a better simulation performance than WRF-UCM for both urban and non-urban areas, whether for daytime or nighttime for whole-month simulations with and without simulated rainfall present. The 1month simulation results are consistent with previous findings (Tables 1 and 2) for a several-day simulation. Again, more significant improvement is observed mainly in nonurban areas during nighttime for a whole-month simulation. WRF-UCM2D yielded a higher $R^{2}$ than WRF-UCM ( 0.73 vs. 0.57 , respectively), while bias and RMSE obtained by WRF-UCM2D were both smaller than those by WRF-UCM ( -0.22 and 1.18 vs. 0.41 and 1.46 , respectively). Taken together, the results reveal that the proposed WRF-UCM2D could be applied to simulation over a long time period.

\section{Factors influencing model performance in non-urban areas during nighttime}

\subsection{Relationship between air temperature and urban fraction}

Table 5 lists the grid-averaged simulation results at different urban fractions during nighttime. The first column shows the diagnostic air temperatures at a height of $2 \mathrm{~m}\left(T_{2} \mathrm{~m}\right)$ obtained by the two models and the calculated difference in their simulation results. Figure 9 plots these differences against urban fractions ranging from 0 to 1 . Each urban fraction along the $x$ axis represents the averaged value of \pm 0.025 urban fraction (i.e., 0.1 represents the mean value between 0.075 and $0.125)$. The numbers of grid points for urban fractions of $0.05,0.1,0.15,0.2,0.25,0.3,0.35$, and 0.4 are $880,501,346$, $368,240,160,72$, and 25 , respectively. The results displayed in Table 5 and Fig. 9a show that the maximum mean temperature difference is $-1.8 \mathrm{~K}$ in model grids with an urban fraction of 0.05 , and the two models yield the same simulated temperature at an urban fraction of 0.2. However, contrasting phenomena in model grids are observed with urban fractions smaller and greater than 0.2. In model grids with an urban fraction $<0.2$, mean air temperatures obtained by WRF-UCM are higher than those by WRF-UCM2D, while the reverse is true for model grids with an urban fraction $>0.2$. With both the effect of urban fraction and AH taken into account, it is not surprising that WRF-UCM2D yields higher mean air temperatures than WRF-UCM when the urban fraction exceeds 0.2. In contrast, it is intriguing to find lower mean air temperatures simulated by WRF-UCM2D with an urban fraction $<0.2$. Such results can be accounted for by the energy budget as discussed below.

\subsection{Sensible heat flux $\left(F_{\text {sh }}\right)$}

As suggested in Chen et al. (2011), the total grid-scale sensible heat flux is averaged with the weighting of the urban fraction contributed from both Noah-LSM (calculated contribution from natural surface) and UCM (calculated contribution from artificial surface). The relationship between sensible heat flux and surface air temperature during nighttime can be expressed as

$F_{\mathrm{sh}}-\sigma T^{4}=\rho_{\mathrm{s}} C_{p} C_{\mathrm{h}}\left(T_{\mathrm{sk}}-T_{2 \mathrm{~m}}\right)$,

where $F_{\mathrm{sh}}$ is the grid-averaged sensible heat flux, $\sigma T^{4}$ is the upward long-wave radiation, $\rho_{\mathrm{s}}$ is the density of surface air, $C_{p}$ is the specific heat capacity of air at constant pressure, $C_{\mathrm{h}}$ is the surface exchange coefficient for heat from the surfacelayer scheme, $T_{\mathrm{sk}}$ denotes ground surface temperature, and $T_{2 \mathrm{~m}}$ stands for diagnostic air temperatures at a height of $2 \mathrm{~m}$.

Table 5 shows the mean value of these parameters of Eq. (1) as obtained by the two models and the calculated differences in their simulation results. Figure $9 \mathrm{~b}, \mathrm{c}$, and d plot, respectively, the differences in $F_{\mathrm{sh}}, \rho_{\mathrm{s}} C_{p} C_{\mathrm{h}}$, and $T_{\mathrm{sk}}$ against urban fractions. As can be seen, for these non-urban model grids with an urban fraction of $\leq 0.4$, WRF-UCM2D yields higher $F_{\mathrm{sh}}, \rho_{\mathrm{s}} C_{p} C_{\mathrm{h}}$, and $T_{\mathrm{sk}}$ than WRF-UCM.

For $F_{\mathrm{sh}}, \mathrm{WRF}-\mathrm{UCM}$ yields negative values, ranging from -9.3 to $-18.26 \mathrm{~W} \mathrm{~m}^{-2}$, for all model grids with an urban fraction $\leq 0.4$, while WRF-UCM2D obtained values, ranging from -10.5 to $9.7 \mathrm{~W} \mathrm{~m}^{-2}$, negative for model grids with an urban fraction $\leq 0.25$ and positive for model grids with an urban fraction $\geq 0.3$. The negative $F_{\mathrm{sh}}$ in WRF-UCM is attributed to radiation cooling after sunset and the absence of extra energy forcing at these non-urban stations during nighttime. The extra energy forcing taken into account by WRF- 
(a)

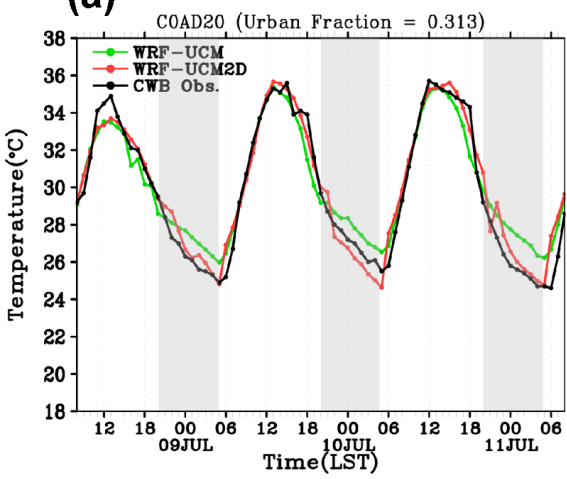

(c)

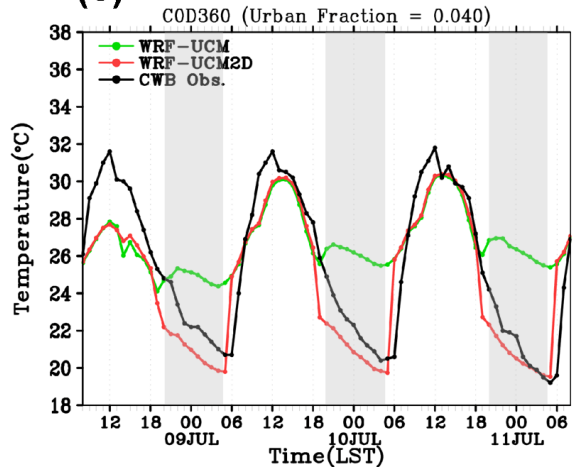

(b)

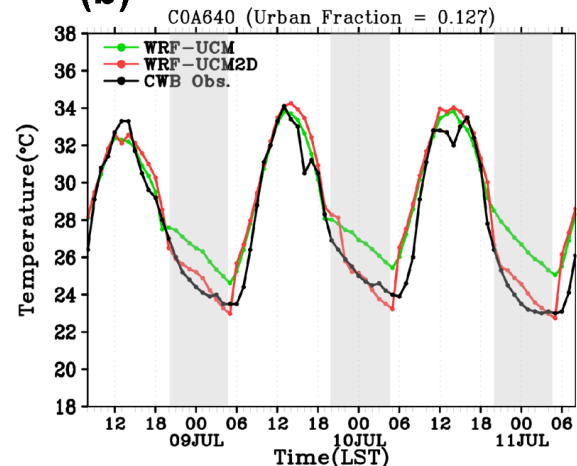

Figure 8. Difference between simulated and observed diurnal variation in temperature at non-urban stations (a) C0AD20, (b) C0A640, and (c) C0D360.

Table 3. Bias, RMSE, and $R^{2}$ calculated using simulated temperatures at 21 non-urban stations for the month of July 2012 , for daytime, and for nighttime obtained by WRF-UCM and WRF-UCM2D. The numbers in parentheses were analysis results after the exclusion of model data where simulated rainfall was found to be present.

\begin{tabular}{|c|c|c|c|c|c|c|}
\hline \multirow[t]{2}{*}{ Non-urban } & \multicolumn{2}{|c|}{ July 2012} & \multicolumn{2}{|c|}{ Daytime } & \multicolumn{2}{|c|}{ Nighttime } \\
\hline & WRF-UCM & WRF-UCM2D & WRF-UCM & WRF-UCM2D & WRF-UCM & WRF-UCM2D \\
\hline $\operatorname{BIAS}\left({ }^{\circ} \mathrm{C}\right)$ & $0.06(0.44)$ & $-0.10(0.01)$ & $-0.15(0.29)$ & $-0.02(0.27)$ & $0.41(0.57)$ & $-0.22(-0.22)$ \\
\hline $\operatorname{RMSE}\left({ }^{\circ} \mathrm{C}\right)$ & $1.53(1.55)$ & 1.38 (1.29) & $1.58(1.53)$ & $1.49(1.43)$ & $1.46(1.56)$ & $1.18(1.14)$ \\
\hline$R^{2}$ & $0.78(0.78)$ & $0.82(0.84)$ & $0.76(0.83)$ & $0.78(0.84)$ & $0.57(0.53)$ & $0.73(0.76)$ \\
\hline
\end{tabular}

UCM2D includes $\mathrm{AH}$ and heat released during nighttime by urban elements that absorb solar energy during daytime. In model grids with an urban fraction $\leq 0.25$, radiation cooling exceeds the extra energy forcing, while in model grids with an urban fraction $\geq 0.3$, the extra energy forcing is large enough to overcome radiation cooling.

The mean differences in $F_{\mathrm{sh}}$, ranging from 2.5 to $19 \mathrm{~W} \mathrm{~m}^{-2}$, show a trend of larger differences in simulated results between the two models at higher urban fractions.

\subsection{Energy exchange $\left(\rho_{\mathrm{s}} C_{p} C_{\mathrm{h}}\right)$}

As shown in Table 5 and Fig. 9c, WRF-UCM2D yields a higher energy exchange than WRF-UCM (16.5-
$25 \mathrm{~W} \mathrm{~m}^{-2} \mathrm{~K}$ vs. $8.5-19.1 \mathrm{~W} \mathrm{~m}^{-2} \mathrm{~K}$, respectively). The simulated results of both models show an increase in energy exchange from an urban fraction of 0.05 to 0.2 , followed by a decrease in energy exchange at urban fractions exceeding 0.2. In other words, energy exchange peaks at an urban fraction of $0.2\left(25 \mathrm{~W} \mathrm{~m}^{-2} \mathrm{~K}\right.$ and $19.1 \mathrm{~W} \mathrm{~m}^{-2} \mathrm{~K}$ by WRFUCM2D and WRF-UCM, respectively). The mean difference in energy exchange ranging from 5.6 to $12.1 \mathrm{~W} \mathrm{~m}^{-2} \mathrm{~K}$ first decreases with increasing urban fraction from 0.05 to 0.15 and then increases with increasing urban fraction $>0.2$. In other words, energy exchange is stronger at a low urban fraction than at a high urban fraction, even though the contribution of extra forcing is insignificant at a lower urban fraction. Energy exchange enables efficient turbulence mixing at 
Table 4. Bias, RMSE, and $R^{2}$ calculated using simulated temperatures at 19 urban stations for the month of July 2012, for daytime, and for nighttime obtained by WRF-UCM and WRF-UCM2D. The numbers in parentheses were analysis results after the exclusion of model data where simulated rainfall was found to be present.

\begin{tabular}{lrrrrrrrr}
\hline \multirow{2}{*}{ Urban } & \multicolumn{2}{c}{ July 2012 } & & \multicolumn{2}{c}{ Daytime } & & \multicolumn{2}{c}{ Nighttime } \\
\cline { 2 - 3 } & WRF-UCM & WRF-UCM2D & & WRF-UCM & WRF-UCM2D & & WRF-UCM & WRF-UCM2D \\
\hline BIAS $\left({ }^{\circ} \mathrm{C}\right)$ & $0.04(0.18)$ & $0.21(0.30)$ & & $0.01(0.22)$ & $0.22(0.38)$ & & $0.10(0.15)$ & $0.19(0.22)$ \\
RMSE $\left({ }^{\circ} \mathrm{C}\right)$ & $1.36(1.23)$ & $1.32(1.16)$ & & $1.41(1.22)$ & $1.40(1.20)$ & & $1.28(1.23)$ & $1.18(1.12)$ \\
$R^{2}$ & $0.75(0.79)$ & $0.77(0.82)$ & & $0.73(0.85)$ & $0.74(0.86)$ & & $0.44(0.49)$ & $0.54(0.59)$ \\
\hline
\end{tabular}

(a)
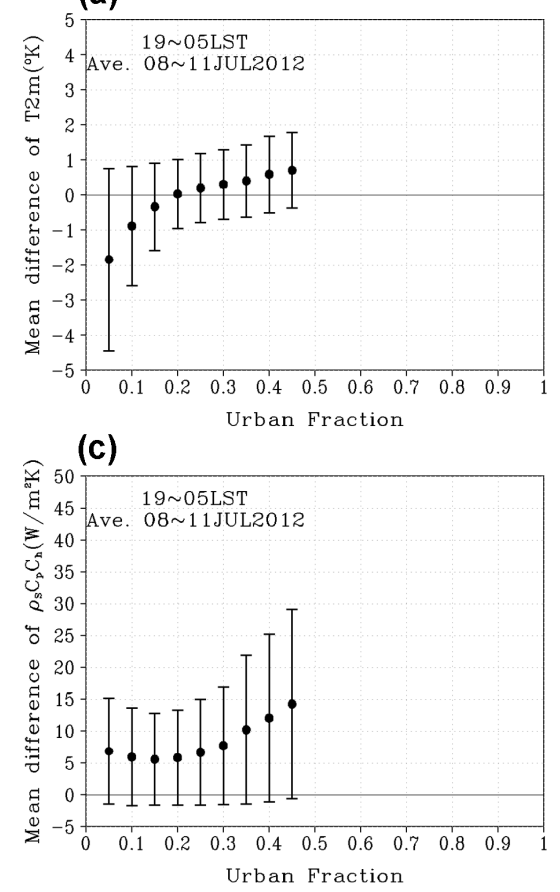

(b)

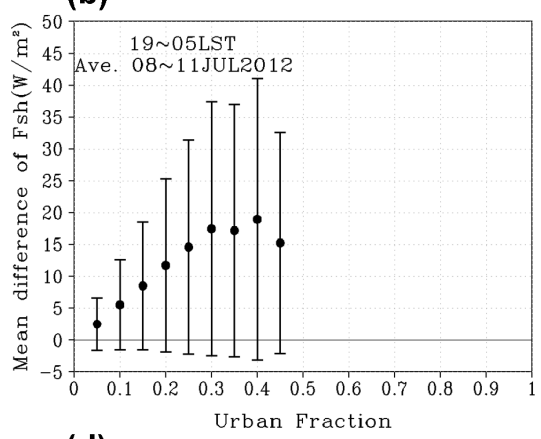

(d)

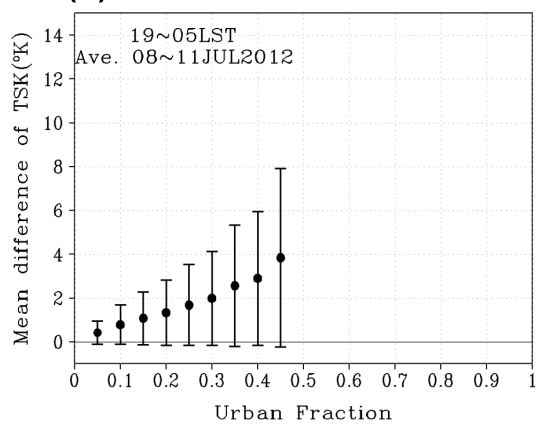

Figure 9. Mean difference in (a) $2 \mathrm{~m}$ air temperature, $T_{2 \mathrm{~m}}$, (b) sensible heat flux, $F_{\mathrm{sh}}$, (c) energy exchange, $\rho_{\mathrm{s}} C_{p} C_{\mathrm{h}}$, and (d) ground surface temperature, $T_{\mathrm{sk}}$, simulated by WRF-UCM2D and WRF-UCM at different urban fractions during nighttime.

a low urban fraction, in particular at an urban fraction $<0.2$, thus reducing air temperature obtained by WRF-UCM2D, followed by a decrease in simulated ground surface temperature $T_{\mathrm{sk}}$.

\subsection{Ground surface temperature $\left(T_{\mathrm{sk}}\right)$}

As shown in Table 5 and Fig. 9d, $T_{\text {sk }}$ obtained by WRFUCM2D and WRF-UCM ranges from 296.9 to $302.1 \mathrm{~K}$ and from 296.5 to $299.2 \mathrm{~K}$, respectively, again showing higher temperatures simulated by WRF-UCM2D than by WRFUCM. Like $F_{\mathrm{sh}}$, the mean difference in $T_{\mathrm{sk}}$, ranging from 0.4 to $2.9 \mathrm{~K}$, shows a trend of larger differences between the two models at higher urban fractions, again owing to the effect of urban fraction and $\mathrm{AH}$ being taken into account by WRF-UCM2D.
The last column in Table 5 lists the temperature difference between the simulated $T_{\mathrm{sk}}$ and $T_{2 \mathrm{~m}}$. As can be seen, the differences obtained by WRF-UCM2D at different urban fractions, ranging from -0.52 to $0.5 \mathrm{~K}$, are insignificant, implying that WRF-UCM2D-simulated air temperatures are close to WRF-UCM2D-simulated ground surface air temperatures. In contrast, the differences obtained by WRF$\mathrm{UCM}$ at different urban fractions, ranging from -2.78 to $-1.44 \mathrm{~K}$, are large, indicating greater discrepancy between WRF-UCM-simulated air temperatures and ground surface air temperatures.

Although the $T_{\text {sk }}$ obtained by WRF-UCM2D at various urban fractions is higher than that obtained by WRF-UCM (fourth column of Table 5), the difference between WRFUCM2D-simulated $T_{\text {sk }}$ and $T_{2 \mathrm{~m}}$ is smaller than that between WRF-UCM-simulated $T_{\text {sk }}$ and $T_{2} \mathrm{~m}$. The better performance of WRF-UCM2D is attributed to more efficient energy ex- 


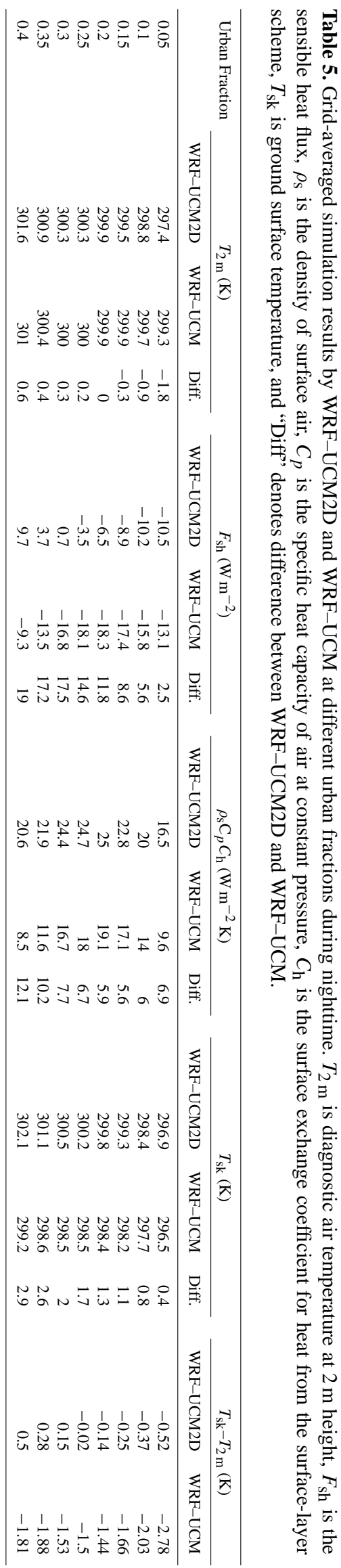

change in the WRF-UCM2D simulation, with urban fraction in non-urban areas also taken into account. As mentioned above, one of the limitations of WRF-UCM is the fixed urban fraction, resulting in mis- or even non-representation of non-urban areas.

Taken together, the results above reveal that the critical urban fraction is about 0.2 , at which the difference in $T_{2} \mathrm{~m}$ between WRF-UCM2D and WRF-UCM is 0. Moreover, energy exchange in both WRF-UCM2D and WRF-UCM simulations peak at an urban fraction of 0.2.

\section{Summary and conclusion}

This study evaluates the impact of urbanization over northern Taiwan using the Weather Research and Forecasting Model coupled with the Noah land-surface model and a modified urban canopy model. In the original UCM, when the land use in the model grid is identified as "urban", the urban fraction value is fixed. For example, in this study, the urban fraction is fixed at 0.7. Similarly, the UCM assumes the distribution of anthropogenic heat to be constant. This may not only lead to over- or underestimation, but the temperature difference between urban and non-urban areas has also been neglected. To overcome the abovementioned limitations and to improve the performance of the original UCM model, WRF-UCM is modified to consider the 2-D urban fraction and AH (WRFUCM2D). WRF-UCM2D provided more detailed and accurate spatial distribution of areas with an urban fraction ranging from 0.01 to 1.0. The spatial distribution of $\mathrm{AH}$ over the entire area studied ranges from 0 to $50 \mathrm{~W} \mathrm{~m}^{-2}$, giving more detailed information at a finer resolution. With the improved model, the oversimplified results can be avoided, with the percentage of urbanization in the model grids more accurately identified according to the actual land use and building density for $\mathrm{AH}$, not only in the city center but also in rural small towns.

Simulation results show that WRF-UCM2D provides a more detailed and accurate spatial distribution of air temperatures, which are sometimes underestimated in urban areas during daytime by WRF-UCM. The two models have comparable simulation performance for urban areas, while large differences in simulated results are observed for nonurban areas, especially at nighttime. WRF-UCM2D yielded a higher $R^{2}$ than WRF-UCM (0.72 vs. 0.48 , respectively), while bias and RMSE produced by WRF-UCM2D were both significantly smaller than those attained by WRF-UCM (0.27 and 1.27 vs. 1.12 and 1.89 , respectively). In other words, the improved model not only enhanced correlation but also reduced bias and RMSE for the nighttime data of nonurban areas. The performance of WRF-UCM2D is much better than WRF-UCM at non-urban stations with a low urban fraction during nighttime. It is attributed to energy exchange that enables efficient turbulence mixing in areas with a low urban fraction (in particular with an urban fraction $<0.2$ ). 
Energy exchange contributes to reduce air temperatures simulated by WRF-UCM2D, followed by a decrease in ground surface temperatures. Moreover, simulation results show that the critical urban fraction is around 0.2 , at which the difference in $T_{2 \mathrm{~m}}$ obtained by WRF-UCM2D and WRF-UCM is 0 . Finally, the proposed WRF-UCM2D successfully improved the simulation of diurnal variation in air temperature in urban and non-urban areas. The results of this study can be applicable when assessing the impacts of urbanization on air quality and regional climate.

Acknowledgements. This work was financially supported by the National Science Council, Taiwan, under grant NSC-102-2111M-001-007 and the thematic project of Academia Sinica, Taiwan, under grant AS-102-SS-A10. Discussion on modeling work with Michael Duda (NCAR) is very much appreciated.

Edited by: S. Galmarini

\section{References}

Arnfield, A. J.: Two decades of urban climate research: A review of turbulence, exchanges of energy and water, and the urban heat island, Int. J. Climatol., 23, 1-26, 2003.

Atkinson, B. W. : Numerical modeling of urban heat island intensity, Bound.-Lay. Meteorol., 109, 285-310, 2003.

Chen, F. and Dudhia, J.: Coupling an advanced land surface hydrology model with the Penn State-NCAR MM5 modeling system. Part I: Model implementation and sensitivity, Mon. Weather Rev., 129, 569-585, 2001.

Chen, F., Kusaka, H., Tewari, M. Bao, J.-W., and Kirakuchi, H.: Utilizing the coupled WRF/LSM/Urban modeling system with detailed urban classification to simulate the urban heat island phenomena over the greater Houston Area, The 5th Conference on Urban Environment, 22-26 August 2004, Vancouver BC, Canada, 2004.

Chen, F., Kusaka, H., Bornstein, R., Grimmond, S., Ching, J., Grimmond, C. S. B., Grossman-Clarke, S., Loridan, T., Manning, K. W., Martilli, A., Miao, S., Sailor, D., Salamanca, F. P., Taha, H., Tewari, M., Wang, X., Wyszogrodzki, A. A., and Zhang, C.: The integrated WRF/urban modelling system: development, evaluation, and applications to urban environmental problems, Int. J. Climatol., 31, 273-288, 2011.

Chen, T.-C., Wang, S.-Y., and Yen, M.-C.: Enhancement of afternoon thunderstorm activity by urbanization in a valley: Taipei, $\mathrm{J}$. Appl. Meteor. Climatol., 46, 1324-1340, 2007.

Corburn, J.: Cities, climate change and urban heat island mitigation: Localizing global environmental science, Urban Studies, 46, 413-427, 2009.

Ek, M. B., Mitchell, K. E., Lin, Y., Rogers, E., Grunmann, P., Koren, V., Gayno, G., and Tarpley, J. D.: Implementation of Noah land surface model advances in the National Centers for Environmental Prediction operational mesoscale Eta model, J. Geophys. Res., 108, 8851, doi:10.1029/2002JD003296, 2003.

Feddema, J. J., Oleson, K. W., Bonna, G. B., Mearns, L. O., Buja, L. E., Meehl, G. A., and Washington, W. M.: The importance of land-cover change in simulating future climates, Science, 310, 1674-1678, 2005.

Grimmond, C. S. B.: The suburban energy balance: Methodological considerations and results for a mid-latitude west coast city under winter and spring conditions, Int. J. Climatol., 12, 481-497, 1992.

Grimmond, C. S. B. and Oke, T. R.: Comparison of heat fluxes from summertime observations in the suburbs of four North American cities, J. Appl. Meteorol., 34, 873-889, 1995.

Holt, T. R. and Pullen, J.: Urban canopy modeling of the New York City metropolitan area: A comparison and validation of singleand multilayer parameterization, Mon. Weather Rev., 135, 19061930, 2007.

Hong, S.-Y. and Lim, J. J.: The WRF Single-Moment 6-Class Microphysics Scheme (WSM6), J. Korean Meteorol. Soc., 42, 129$151,2006$.

Huszar, P., Halenka, T., Belda, M., Zak, M., Sindelarova, K., and Miksovsky, J.: Regional climate model assessment of the urban land-surface forcing over central Europe, Atmos. Chem. Phys. 14, 12393-12413, doi:10.5194/acp-14-12393-2014, 2014.

IPCC: Climate change 2007: Impacts, adaptation and vulnerability. Rep., Contribution of Working Group II to the Fourth Assessment Report of the Intergovernmental Panel on Climate Change. Cambridge, UK, Cambridge University Press, 2007.

IPCC: Climate Change 2013: The Physical Science Basis. Contribution of Working Group I to the Fifth Assessment Report of the Intergovernmental Panel on Climate Change, Cambridge University Press, Cambridge, United Kingdom and New York, NY, USA, 1535 pp., doi:10.1017/CBO9781107415324, 2013.

Jin, M., Shepherd, J. M., and King, M. D.: Urban aerosols and their interaction with clouds and rainfall: A case study for New York and Houston, J. Geophy. Res., 1110, D10S20, doi:10.1029/2004JD005081, 2005.

Kalnay, E. and Cai, M.: Impact of urbanization and land-use change on climate, Nature, 423, 528-531, 2003.

Kang, H. Q., Zhu, B., Zhu, T., Sun, J. L., and Ou, J. J.: Impact of megacity Shanghai on the urban heat island effects over the downstream city Kunshan, Bound.-Lay. Meteorol., 152, 411426, 2014.

Koster, R. D., Dirmeyer, P. A., Guo, Z., Bonan, G., Chan, E., Cox, P., Gordon, C. T., Kanae, S., Kowalczyk, E., Lawrence, D., Liu, P., Lu, C. H., Malyshev, S., Mcavaney, B., Mitchell, K., Mocko, D., Oki, T., Oleson, K., Pitman, A., Sud, Y. C., Taylor, C. M., Verseghy, D., Vasic, R., Xue, Y., and Yamada, T.: Regions of strong coupling between soil moisture and precipitation, Science, 305, 1138-1140, 2004.

Kunkel, K. E., Changnon, S. A., Reinke, B. C., and Arritt, R. W.: The July 1995 heat wave in the Midwest: A climatic perspective and critical weather factors, B. Am. Meteorol. Soc., 77, 15071518, 1996.

Kusaka, H. and Kimura, F.: Coupling a single-layer urban canopy model with a simple atmospheric model: Impact on urban heat island simulation for an idealized case, J. Appl. Meteor., 43, 1899_ 1910, 2004.

Kusaka, H., Kondo, K., Kikegawa, Y., and Kimura, F.: A simple single-layer urban canopy model for atmospheric models: Comparison with multi-layer and slab models, Bound.-Lay. Meteor. 101, 329-358, 2001. 
Kusaka, H., Chen, F., and Tewari, M.: Impact of using the urban canopy model on the simulation of the heat island of Tokyo, Extended Abstracts, Sixth Symp. on the Urban Environment,Atlanta, GA, Amer. Meteor. Soc., J1.3., 2006.

Kusaka, H., Hara, M., and Takane, Y.: Urban climate projection by the WRF model at 3-km horizontal grid increment: Dynamical downscaling and predicting heat stress in the 2070's August for Tokyo, Osaka, and Nagoya metropolises, J. Meteor. Soc. Japan, 90B, 47-63, 2012a.

Kusaka, H., Chen, F., Tewari, M., Dudhia, J., Gill, D. O., Duda, M. G., Wang, W., and Miya, Y.: Numerical simulation of urban heat island effect by the WRF model with 4-km grid increment: An inter-comparison study between the urban canopy model and slab model, J. Meteor. Soc. Japan, 90B, 33-45, 2012 b.

Kusaka, H., Nawata, K., Suzuki-Parker, A., Takane, Y., and Furuhashi, N.: Mechanism of precipitation increase with urbanization in Tokyo as revealed by ensemble climate simulations, J. Appl. Meteor. Clim., 53, 824-839, 2014.

Liao, J., Wang, T., Wang, X., Xie, M., Jiang, Z., Huang, X., and Zhu, J.: Impacts of different urban canopy schemes in WRF/Chem on regional climate and air quality in the Yangtze River Delta, China, Atmos. Res., 145-146, 226-243, 2014.

Lin, C.-Y., Chen, W.-C., Liu, S. C., Liou, Y. A., Liu, G. R., and Lin, T.-H.: Numerical study of the impact of urbanization on the precipitation over Taiwan, Atmos. Environ., 42, 2934-2947, 2008 a.

Lin, C.-Y., Chen, F., Huang, J., Liou, Y. A., Chen, W. C., Chen, W. N., and Liu, S. C.: Urban heat island effect and its impact on boundary layer development and land-sea circulation over Northern Taiwan, Atmos. Environ., 42, 5639-564, 2008b.

Lin, C.-Y., Chen, W. C., Chang, P.-L., and Sheng, Y. F.: Impact of urban heat island effect on the precipitation over complex geographic environment in northern Taiwan, J. Appl. Meteorol. Climatol., 50, 339-353, doi:10.1175/2010JAMC2504.1, 2011.

Liu, Y., Chen, F., Warner, T., and Basara, J.: Verification of a mesoscale data-assimilation and forecasting system for the Oklahoma city area during the Joint Urban 2003 Field Project, J. Appl. Meteorol., 45, 912-929, 2006.

Lo, J. C. F., Lau, A. K. H., Chen, F., Fung, J. C. H., and Leung, K. K. M.: Urban modification in a mesoscale model and the effects on the local circulation in the Pearl River Delta Region, J. Appl. Meteorol. Climatol., 46, 457-476, 2007.
Martilli, A., Clappier, A., and Rotach, M. W.: An urban surface exchange parameterization for mesoscale models, Bound.-Lay. Meteorol., 104, 261-304, 2002.

Miao, S., Chen, F., LeMone, M. A., Tewari, M., Li, Q., and Wang, Y.: An observational and modeling study of characteristics of urban heat island and boundary layer structures in Beijing, J. Appl. Meteorol. Climatol., 48, 484-501, 2009.

Oke, T. R.: The energetic basis of the urban heat island, Q. J. R. Meteorol. Soc. 108, 1-24, 1982.

Ren, G. Y., Chu, Z. Y., Chen, Z. H., and Ren, Y. Y.: Implications of temporal change in urban heat island intensity observed at Beijing and Wuhan stations, Geophys. Res. Lett., 34, L05711, doi:10.1029/2006GL027927, 2007.

Rizwan, A. M., Leung, Y. C., and Liu, C.: A review on the generation, determination and mitigation of Urban Heat Island, J. Environ. Sci., 20, 120-128, 2008.

Sailor, D. J.: A review of methods for estimating anthropogenic heat and moisture emissions in the urban environment, Int. J. Climatol., 31, 189-199, 2011.

Sailor, D. J. and Lu, L.: A top-down methodology for developing diurnal and seasonal anthropogenic heating profiles for urban areas, Atmos. Enviro., 38, 2737-2748, 2004.

Skamarock, W. C., Klemp, J. B., Dudhia, J., Gill, D. O., Barker, D. M., Duda, D. M., Wang, W., and Powers, J. G.: A description of the advanced research WRF version 3, NCAR Tech. Note. NCAR/TN-468+STR, 100 pp., Natl. Cent. for Atmos. Res., Boulder, Colo, 2008.

Tan, J., Zhang, Y., Tang, X., Cuo, C., Li, L., Song, G., Zhen, X., Yuan, D., Kalkstein, A. J., Li, F., and Chen, H.: The urban heat island and its impact on heat waves and human health in Shanghai, Int. J. Biometeorol., 54, 75-84, 2010.

Tewari, M., Chen, F., and Kusaka, H.: Implementation and evaluation of a single-layer urban model in WRF/Noah, The 7th WRF Users' Workshop, June 2006.

Wang, X., Liao, J., Zhang, J., Shen, C., Chen, W., Xia, B., and Wang, T.: A numerical study of regional climate change induced by urban expansion in the Pearl River Delta, J. Appl. Meteor. Climatol., 53, 346-362, 2014. 